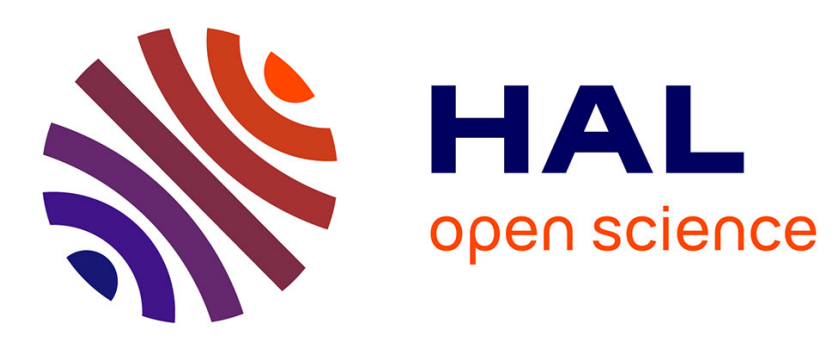

\title{
Ultra-small-angle X-ray scattering study of the structure of colloidal and polymeric systems
}

\author{
H. Matsuoka, Y. Nakatani, M. Yamakawa, N. Ise
}

\section{To cite this version:}

H. Matsuoka, Y. Nakatani, M. Yamakawa, N. Ise. Ultra-small-angle X-ray scattering study of the structure of colloidal and polymeric systems. Journal de Physique IV Proceedings, 1993, 03 (C8), pp.C8-451-C8-454. 10.1051/jp4:1993893 . jpa-00252324

\section{HAL Id: jpa-00252324 https://hal.science/jpa-00252324}

Submitted on 1 Jan 1993

HAL is a multi-disciplinary open access archive for the deposit and dissemination of scientific research documents, whether they are published or not. The documents may come from teaching and research institutions in France or abroad, or from public or private research centers.
L'archive ouverte pluridisciplinaire $\mathbf{H A L}$, est destinée au dépôt et à la diffusion de documents scientifiques de niveau recherche, publiés ou non, émanant des établissements d'enseignement et de recherche français ou étrangers, des laboratoires publics ou privés. 


\title{
Ultra-small-angle X-ray scattering study of the structure of colloidal and polymeric systems
}

\author{
H. MATSUOKA, Y. NAKATANI, M. YAMAKAWA and N. ISE*
}

Department of Polymer Chemistry, Kyoto University, Kyoto 606-01, Japan

${ }^{*}$ Fukui Research Laboratory, Rengo Co. Ltd., Jiyugaoka, Kanazu-cho, Sakai-gun, Fukui 919-06, Japan

\begin{abstract}
We have constructed the Bonse-Hart type Ultra-small-angle $x-r a y$ scattering (USAXS) instrument to study large-scale density fluctuations in colloidal and polymer systems. Our USAXS instrument has very high small-angle resolution up to 8 micrometers. The USAXS curves from polymer latex dispersions at very low ionic strength showed clear Bragg peaks, indicating that the ordered structure of latex particles was formed even inside dispersions by the electrostatic interactions between the particles. The lattice system and lattice constant could be precisely estimated. The time evolution of the USAXS curve reflecting the ordered structure formation was also examined. The microdomain structure of polymer alloy systems and microcrystalline structure of polypropylene film were also investigated. The USAXS technique enables us to investigate submicron structures in various systems which could not be studied by other techniques.
\end{abstract}

I. Introduction

It was in 1966 when Bonse and Hart constructed a new type of small-angle scattering instrument of a very high resolution [1]. However, unfortunately, few systematic study has been done by this type of instrument. This is probably because there was no demand to study structures of such a large dimension and also because of the difficulty of construction of such a high performance apparatus. In recent years, structural investigations of large dimensions attract keen attentions. The typical examples may be colloid crystals [2] and microphase structures of polymer and metal alloys. These systems cannot be studied by light scattering since they are turbid or opaque. Microscopic techniques (optical and electron) can provide mostly twodimensional, local structure. Moreover, the electron microscope technique can be applied only to solid samples. To overcome these difficulties, we constructed an ultra-small-angle $\mathrm{X}$-ray scattering (USAXS) instrument of Bonse-Hart (B-H) type to study the structure of colloid crystals and large scale density fluctuation in polymeric systems [35]. The compact $B-H$ system enables us to carry out structural studies in laboratory scale while long-distance camera needs large spaces and huge size instrumentation.

\section{Experimental}

Figure 1 shows the optical system of our Bonse-Hart type USAXS instrument. For the first (monochromator) and the second (analyzer) grooved crystals, we used silicon single crystals since highly perfect crystals can be obtained (it is reported that there are only a few crystal defects in $1 \mathrm{~cm}^{2}$ ). The $\mathrm{X}$-rays repeat 5 times Bragg reflections in each crystal groove. The minimum step of the rotation of the second crystal is $0.01 \mathrm{sec}$. The FWHM of the direct beam was only 4 seconds, implying that the small-angle resolution of this instrument is about 8 micrometers. The lower limit could be calculated to be about $300 \AA$ by the geometrical requirement. This measurable range corresponds to $10^{-5}-10^{-2} \AA$ in $q-s p a c e$. The whole optical system was set in the cylin- 
drical vacuum chamber to avoid the scattering and absorption by air. The intensity fluctuation of the incident beam was corrected by a monitor counter which was located behind the second crystal. The five thin Al films were used as attenuators to cover a very large range of intensity. The details were fully described elsewhere[4].

\section{Results and Discussion}

Figure 2 shows USAXS patterns of latex particles in powder state and in dispersion. The theoretical scattering curve of a sphere of radius $3000 \&$ was also shown for comparison. The maxima in the curve were the characteristic ones for a sphere, and their positions depended on the size of sphere. The agreements between experimental and theoretical ones were satisfactory, indicating that the radius of the sphere was about $3000 \AA$. However, strictly, the positions of maxima were different in powder and dispersion: the ones from dispersions appeared at smaller scattering angles. This observation may mean swelling effect of latex particles in dispersion. The radii were calculated from the maximum position to be 2800 and $2900 \AA$ for powder and in dispersion, respectively. The USAXS technique can detect such a small difference precisely. For the colloidal dispersion study, needless to say, the information of the exact size of colloid particle in dispersion (not in powder state) is necessary. It may be also possible to estimate the size distribution by an analysis of maximum profile.

When the ionic impurities are removed by ion exchange resins (i.e. at very low ionic strengths), the latex particles are arranged in an ordered manner (lattice-like structure) due to an electrostatic interparticle interaction. The ordered structure formation has been confirmed by ultramicroscope technique [2]. However, since the field of vision of the microscope is limited to a narrow area which is close to the cell glass surface, it has not been clear that the ordered structure is also maintained inside the dispersion. Figure 3 shows the time evolution of USAXS pattern of latex dispersion containing with ion exchange resins. The growth of the Bragg diffraction peak reflecting an

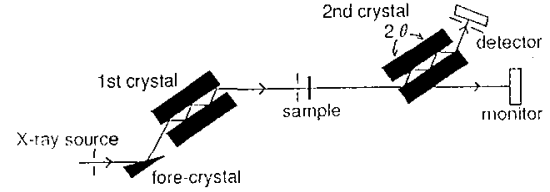

Fig. 1 The optical system of the Ultra-Small-Angle $\mathrm{X}$-ray Scattering (USAXS) apparatus.

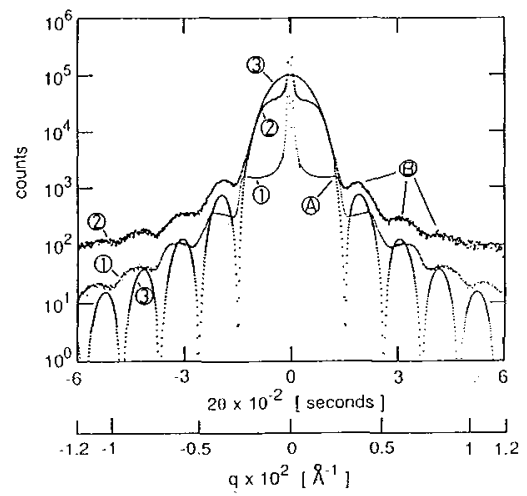

Fig. 2 USAXS curve of SS-80 latex (stated diameter $=3000 \AA$ ) and theoretical curve of a sphere (diameter $=3000 \AA$ ). The peak (A) results from an interparticle interference, and peaks (B) from the shape of the latex.

1:powder sample, cps.

2:suspension (in ethanol) sample, cpsx 100.

3:theoretical curve of a sphere.

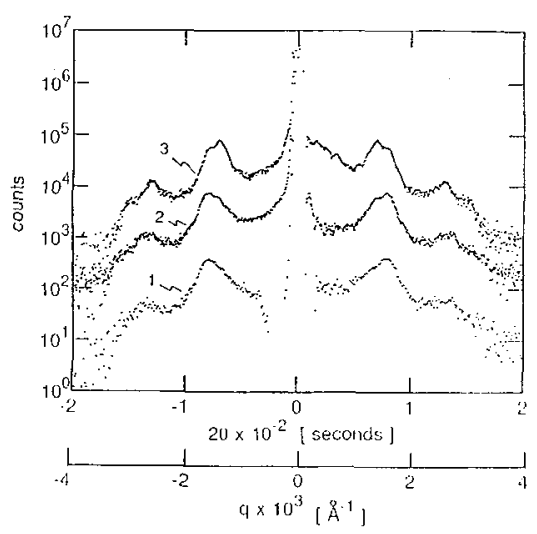

Fig. 3 Time evolution of the scattering curve of SS-121 latex dispersed in water-ethanol mixture. The curve 1,2 and 3 are of 1 week, 2 weeks and 4 weeks after sample preparation, respectively. Curve 2 and 3 are shifted vertically by 1 and 2 decades.

Latex conc. $=3.7$ vol. $\%$, Water:ethanol $=3: 2$ in volume, Accumulation time $=30$ seconds.

Angle Step $=1$ second 
ordered structure formation was clearly observed. The structure was certainly maintained inside the dispersion. From the relative peak positions, the final lattice system of the structure could be judged to be face-centered cubic ( $f c c)$.

At low latex concentration, it has been confirmed that the ordered structure is not maintained throughout the dispersion but exists as clusters of a limited size in coexistence with disordered regions. such a structure is called "two-state structure"[2]. This structure has been observed by microscope. However, it has been claimed that some kind of effects of cell glass is the origin of the structure. To clarify this point, the microscope technique is not suitable. For "two-state structure", the interparticle distance experimentally obtained should be smaller than the calculated one from concentration assuming uniform distribution $\left(2 D_{0}\right)$. Figure $4(a)$ shows the scattering curve at a low latex concentration after purification by resins for 6 weeks, and Fig.4(b) shows the time change of the interparticle distance calculated from peak position $\left(2 \mathrm{D}_{\text {exp }}\right)$. This value became smaller with passing time and smaller than $2 \mathrm{D}_{0}^{\mathrm{p}}$. This observation clearly indicates that "two-state structure" was maintained inside the dispersion (not only in the part close to cell glass surface).

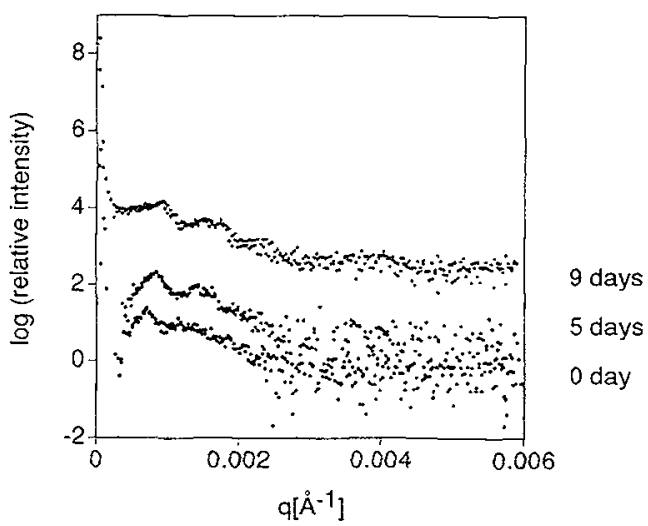

Fig. 4 (a)USAXS curves of MC8 latex dispersed in water. Latex conc. $=1.3 \mathrm{vol} . \%$.

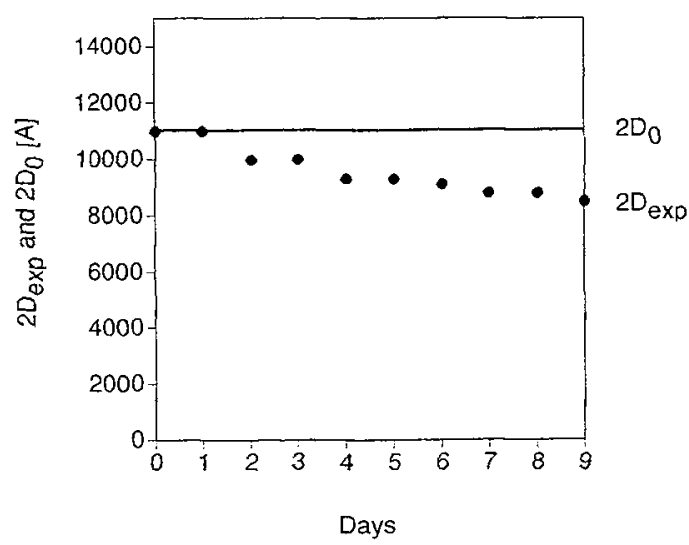

Fig.4(b) Measured nearestneighbor interparticle distance (2Dexp) at various days.

Figure 5 shows the USAXs profile of polymer alloy systems. The electron micrograph showed there are two kinds of spherical domains in this ABS resin. The estimation of the average sizes of these domains by this photograph was very difficult because the picture was showed just a cross-section of this material. However, by USAXS, the analysis by Guinier method gave us the average size in situ, easily and precisely. The initial slope of Guinier plot gave the radius of $2840 \AA$. An excellent linearity could be also observed in larger scattering angles, whose slope gave the radius of $1220 \AA$. These values agreed well with the microscopic observation.

Figure 6 shows the USAXS curves reflecting the size of microcrystal in polypropylene (PP) films. PP films are sometimes transparent and sometimes opaque depending on preparation conditions. Its origin has been thought to be the difference in the size of microcrystals in the film, but no qualitative investigation could be done. The USAXS curves for three films of various transparencies clearly showed the difference: the turbid sample displayed a very strong scattering in very smal1-angle regions. By Guinier analysis, the radius of gyration (Rg) of microcrystals were 1410,600 and $390 \AA$, for turbid and two translucent samples, respectively.

IV. Conclusions

The USAXS instrument we have constructed has a very high small- 
angle resolution upto 8 micrometers, and this is a very powerful tool to study the structure of colloidal dispersions and polymer systems. A large scale density fluctuations in various colloidal and polymer systems would be newly found by this technique, which clarify the structure-property relation, which could not have been investigated.

(a)
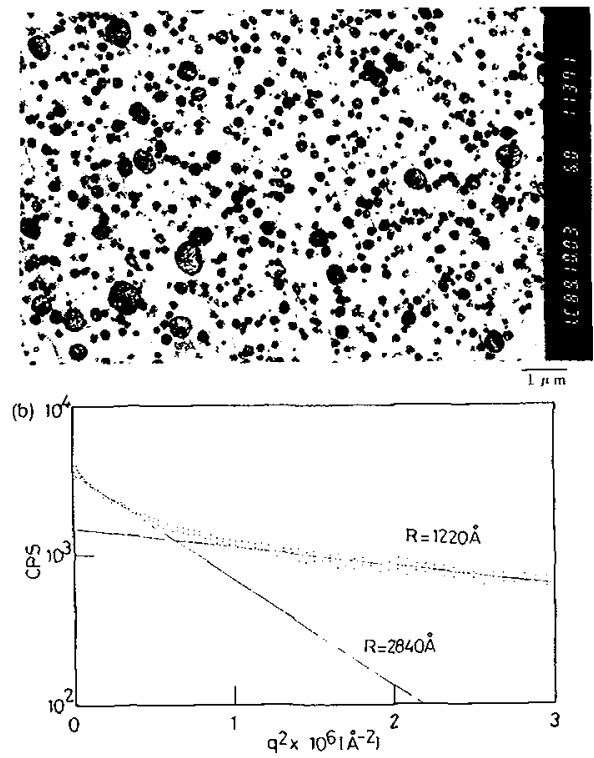

Fig.5 (a) Electronmicrograph of TFX 210. (b) Guinier plot of USAXS data for TFX 210.

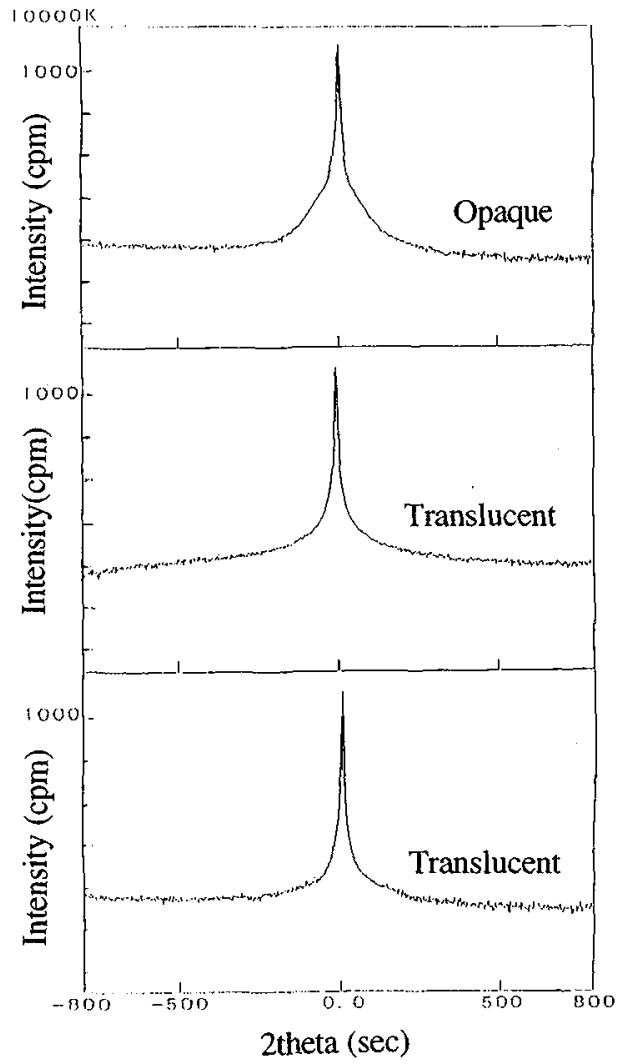

Fig.6USAXS profiles of PP films.

References

[1] Bonse U. and Hart M., Z. Physik 189 (1966) 151.

[2] Ise N., Angew.Chem., 25 (1986) 323.: Dosho S. et al., Langmuir 9 (1993) 394 .

[3] Matsuoka H., et al., Proc.Nat1.Acad.Sci.USA 88 (1991) 6618.

[4] Matsuoka H., Kakigami K., Ise N., The Rigaku Journal 8 (1991) 21.

[5] Matsuoka K., Kakigami K., Ise N., Proc.Japan Acad. 67B (1991) 170. 